\section{Response to: 'Correspondence on 'Concomitant use of oral glucocorticoids and proton pump inhibitors and risk of osteoporotic fractures among patients with rheumatoid arthritis: a population-based cohort study" by Zheng}

We thank Dr Zheng for his comments on our recently published article in the Annals of the Rheumatic Diseases entitled 'Concomitant use of oral glucocorticoids and proton pump inhibitors and risk of osteoporotic fractures among patients with rheumatoid arthritis: a population-based cohort study'. ${ }^{12}$ Our main goal in this study was to bring more clinical insight into the simultaneous use of these two common medications in patients with rheumatoid arthritis (RA), that is, oral glucocorticoids (GCs) and proton pump inhibitors (PPIs), using data from a large primary care database and pharmacoepidemiological methodologies.

Our results showed that there was an interaction in the risk of osteoporotic (OP) fractures with concomitant use of oral GCs and PPIs in patients with RA. Based on the adjusted hazard ratios and according to the formula proposed by Rothman et al, ${ }^{3}$ the relative excess risk due to interaction (RERI) was: $1.60-1.23-$ $1.22+1=0.15$. We now have also calculated the CIs and the statistical significance of this index using the method proposed by Hosmer and Lemeshow. ${ }^{45}$ The lower and upper limits of the $95 \% \mathrm{CI}$ of the RERI were -0.16 and 0.45 , respectively, and the $\mathrm{p}$ value was 0.36 . This means, although we observed a $15 \%$ more risk of OP fracture with concomitant use of oral GCs and PPIs in addition to the single use of each drug versus non-use of both, this additive interaction was not statistically significant.

As we discussed in our paper, there is currently no proven biological mechanism for an action of PPIs on bone or falling, ${ }^{6}$ while the effects of GCs on bone and the musculoskeletal system are quite established. Our secondary analyses (ie, lower fracture risk with long-term or higher daily doses of PPIs compared with short-term or lower daily doses) did not support the few proposed potential mechanisms, such as hypochlorhydria and calcium malabsorption, or an increased fall risk due to malabsorption of magnesium or vitamin $\mathrm{B}_{12}$. This is important to consider when interpreting a potential additive interaction between oral GCs and PPIs on fracture risk. Without this basic knowledge, it would be extremely difficult to confer any conclusions on a plausible synergistic action of these two drugs, since it would sound more as a methodological reasoning rather than a clinical explanation.

Shahab Abtahi $\odot$, 1,2,3 Johanna H M Driessen, ${ }^{1,2,3,4}$ Andrea M Burden (1) 1,5 Patrick C Souverein, ${ }^{2}$ Joop P van den Bergh, ${ }^{6,7,8}$ Tjeerd P van Staa, ${ }^{2,9}$ Annelies Boonen ${ }^{\circ},{ }^{6,10}$ Frank de Vries ${ }^{1,2,3,11}$

${ }^{1}$ Department of Clinical Pharmacy and Toxicology, Maastricht University Medical Centre, Maastricht, The Netherlands

${ }^{2}$ Division of Pharmacoepidemiology and Clinical Pharmacology, Utrecht Institute for Pharmaceutical Sciences, Utrecht University, Utrecht, The Netherlands

${ }^{3}$ Cardiovascular Research Institute Maastricht (CARIM), Maastricht University, Maastricht, The Netherlands

${ }^{4}$ NUTRIM School for Nutrition and Translational Research in Metabolism, Maastricht University Medical Centre, Maastricht, The Netherlands

5 Institute of Pharmaceutical Sciences, Department of Chemistry and Applied Biosciences, ETH-Zurich, Zurich, Switzerland

${ }^{6}$ Department of Internal Medicine, Division of Rheumatology, Maastricht University Medical Centre, Maastricht, The Netherlands

${ }^{7}$ Faculty of Medicine and Life Sciences, Hasselt University, Hasselt, Belgium

${ }^{8}$ Department of Internal Medicine, VieCuri Medical Centre, Venlo, The Netherlands ${ }^{9}$ Centre for Health Informatics, Division of Informatics, Imaging and Data Science, School of Health Sciences, Faculty of Biology, Medicine and Health, The University of Manchester, Manchester, UK
${ }^{10}$ Care and Public Health Research Institute (CAPHRI), Maastricht University, Maastricht, The Netherlands

${ }^{11}$ MRC Epidemiology Lifecourse Unit, Southampton General Hospital, Southampton, UK

Correspondence to Prof Frank de Vries, Division of Pharmacoepidemiology and Clinical Pharmacology, Utrecht Institute for Pharmaceutical Sciences, Utrecht University, PO BOX 80082, 3508 TB, Utrecht, The Netherlands; f.devries@uu.n

Correction notice This article has been corrected since it published Online First. Reference 3 has been corrected.

Handling editor Josef S Smolen

Twitter Shahab Abtahi @Sh_Abtahi and Andrea M Burden @ETH_PharmEpi

Contributors SA and JD conducted the data analysis. All authors contributed to data interpretation. SA wrote the manuscript. All authors were involved in editing or quality control. All authors are accountable for their own contribution, in addition to all aspects of the manuscript. All authors have approved the submitted version of the manuscript.

Funding The authors have not declared a specific grant for this research from any funding agency in the public, commercial or not-for-profit sectors.

Competing interests JvdB reports grants from Amgen, Eli Lilly and UCB, outside the submitted work. $A B$ received research grants to her department from Celgene and AbbVie, and speakers' fees or honoraria from Sandoz, UCB, Lilly, Novartis and Biogen, and Gilead also to her department, not related to the current study. FdV supervises 3 PhD students who are employed with F. Hoffmann La Roche Ltd (Basel, Switzerland/Welwyn Garden City, UK). He has not received any fees or reimbursements for this, and the topics of their PhD thesis are not related to the current study proposal. SA, JD, AMB, PCS and TPvS have no competing interests.

Patient and public involvement Patients and/or the public were not involved in the design, or conduct, or reporting or dissemination plans of this research.

Patient consent for publication Not required.

Provenance and peer review Commissioned; internally peer reviewed.

(c) Author(s) (or their employer(s)) 2021. No commercial re-use. See rights and permissions. Published by BMJ.

\section{Check for updates}

To cite Abtahi S, Driessen JHM, Burden AM, et al. Ann Rheum Dis Epub ahead of print: [please include Day Month Year]. doi:10.1136/annrheumdis-2021-219856

Received 25 January 2021

Accepted 26 January 2021

\section{Linked}

- http://dx.doi.org/10.1136/annrheumdis-2020-219797

Ann Rheum Dis 2021;0:1. doi:10.1136/annrheumdis-2021-219856

ORCID iDs

Shahab Abtahi http://orcid.org/0000-0003-0482-5563

Andrea M Burden http://orcid.org/0000-0001-7082-8530

Annelies Boonen http://orcid.org/0000-0003-0682-9533

\section{REFERENCES}

1 Abtahi S, Driessen JHM, Burden AM, et al. Concomitant use of oral glucocorticoids and proton pump inhibitors and risk of osteoporotic fractures among patients with rheumatoid arthritis: a population-based cohort study. Ann Rheum Dis 2020. doi:10.1136/annrheumdis-2020-218758. [Epub ahead of print: 11 Dec 2020].

2 Zheng B. Correspondence on 'Concomitant use of oral glucocorticoids and proton pump inhibitors and risk of osteoporotic fractures among patients with rheumatoid arthritis: a population-based cohort study'. Ann Rheum Dis 2021.

3 Rothman KJ, Greenland S, Lash TL. Modern Epidemiology. In: Chapter 16, application of stratified analysis methods: analyses of biologic interactions. $3^{\text {rd }}$ ed. Philadelphia (PA, USA: Lippincott Williams \& Wilkins, 2008: 298-9.

4 Hosmer DW, Lemeshow S. Confidence interval estimation of interaction. Epidemiology 1992:3:452-6.

5 Li R, Chambless L. Test for additive interaction in proportional hazards models. Ann Epidemiol 2007; 17:227-36.

6 Andersen BN, Johansen PB, Abrahamsen B. Proton pump inhibitors and osteoporosis. Curr Opin Rheumatol 2016:28:420-5. 